\title{
Yurisdiksi Indonesia terhadap Pelaku Kejahatan Anak Buah Kapal Long Xing 629 di Laut Lepas berdasarkan Hukum Internasional
}

\author{
Fikri Zulfikar Athiansyah", Mohammad Husni Syam
}

Prodi Ilmu Hukum, Fakultas Hukum, Universitas Islam Bandung, Indonesia.

*fikrizulfikara007@gmail.com, mhsyam@gmail.com

\begin{abstract}
Indonesia is the third largest supplier country in the world for fishery workers. Crews who work on national and foreign vessels are often victims of human trafficking in the fishing industry. In this study, cases were taken regarding crimes against Indonesian crew members on the Long Xing 629 ship, the crimes were in the form of trafficking in persons and exploitation of workers. Human trafficking that occurs in the fishing industry aims to exploit workers, in this case crew members. Trafficking in persons and exploitation of workers has been regulated by several international conventions. Trafficking in persons and exploitation of workers are crimes against a person's freedom, both types of international crimes are also included in modern forms of slavery. With respect to crimes that occurred against Indonesian crew members, Indonesia has two jurisdictional powers, namely passive personal jurisdiction based on the existence of material and non-material losses experienced by Indonesian crew members, and universal jurisdiction based on the fact that modern slavery crimes are seen as a matter of serious concern. all nations and belongs to the type of crime against humanity because it is considered to be harmful to human values and justice.
\end{abstract}

Keywords: Human Trafficking, Force Labour, Jurisdiction on High Seas.

\begin{abstract}
Abstrak. Indonesia merupakan negara pemasok terbesar ketiga di dunia untuk tenaga kerja perikanan. ABK yang bekerja di kapal nasional maupun kapal asing sering menjadi korban perdagangan orang di industri perikanan. Dalam penelitian ini kasus yang diambil mengenai kejahatan terhadap ABK WNI di kapal Long Xing 629, kejahatan tersebut berbentuk perdagangan orang dan eksploitasi pekerja. Perdagangan orang yang terjadi di industri perikanan bertujuan untuk mengeksploitasi para pekerja, dalam hal ini ABK. Perdagangan orang dan eksplotasi pekerja sendiri telah diatur dalam oleh beberapa konvensi Internasional. Perdangan orang dan eksploitasi pekerja merupakan ejahatan terhadap kebebasan seseorang, kedua jenis kejahatan internasional tersebut juga termasuk kedalam bentuk perbudakan modern. Terhadap kejahatan yang terjadi kepada ABK WNI tersebut Indonesia memiliki dua kewenagan yurisdiksi, yakni yurisdiksi personal pasif yang didasarkan dengan adanya kerugian baik materil ataupun non materil yang dialami oleh ABK WNI, dan yurisdiksi universal yang didasarkan bahwa kejahatan perbudakan modern dipandang sebagai masalah yang menjadi perhatian serius semua bangsa dan termasuk kepada jenis kejahatan terhadap kemanusiaan karena dinilai dapat membahayakan nilai-nilai kemanusiaan dan keadilan.
\end{abstract}

Kata Kunci: Perdagangan Orang, Eksploitasi Pekerja, Yurisdiksi di Laut Lepas. 


\section{A. Pendahuluan}

Berdasarkan data yang diterbitkan Kementerian Perhubungan RI pada 8 Februari 2020, Indonesia merupakan negara pemasok terbesar ketiga di dunia untuk tenaga kerja perikanan, dengan 1,2 juta tenaga kerja. Namun disisi lain terbatasnya calon ABK yang memiliki pendidikan, atau keterampilan khusus terkait pekerjaan ini menjadi ruang tersendiri bagi maining agency dan perusahaan perikanan untuk merekrut para calon ABK untuk meraup keuntungan sebesar-besarnya dari ketidakpahaman kontrak atau perjanjian kerja laut yang disepakati dan ditandatangani para calon ABK. ABK yang bekerja di kapal nasional maupun kapal asing sering menjadi korban perdagangan orang di industri perikanan. Mereka sangat rentan untuk dieksploitasi, dalam hal ini menjadi korban pelanggaran Hak Asasi Manusia (HAM).

Pada bulan Mei 2020 terdapat sebuah kasus perdagangan orang (human trafficking) dan eksplotasi kerja (forced labour) yang bermula dari viralnya video yang ditayangkan media Korea Selatan, MBC News. Dari vidio tersebut terungkap bahwa terdapat praktek human trafficking dan forced labour terhadap ABK WNI di kapal Long Xing 629. Pada awalnya terdapat 22 Warga Negara Indonesia (WNI) yang dijanjikan oleh "sponsor" untuk bekerja dan diberangkatkan ke luar negeri di kapal berbendera Korea Selatan, dengan gaji sebesar 4.200 U.S Dollar untuk 14 bulan waktu kerja. Dari para sponsor tersebut kemudian 22 WNI tersebut dihubungkan kepada perusahaan penyalur tenaga kerja (maining agency), dan dikirim ke Busan, Korea Selatan karena kapal China itu memiliki kantor cabang di Korsel, adapun nama perusahaannya adalah Dalian Ocean Fishing Co. Ltd.

Praktek yang dimaksud mengacu kepada sistem jam kerja ABK WNI yang mencapai $15 \mathrm{jam} / \mathrm{hari}$, pemberian waktu istirahat yang terbatas karena hanya 15 menit, kebutuhan pokok yang tidak layak, dimana ABK WNI diberikan makanan expired serta makanan untuk diberikan pada ikan, ayam yang dibekukan di freezer, ikan lama yang sudah lama ada di freezer, dan air minum dari air laut yang disuling menggunakan mesin. Selain itu para ABK WNI juga diperlakukan dengan kasar oleh para atasan berupa kekerasan fisik, dan diberikan ancaman akan adanya sanksi kontrak kerja serta penahanan dokumen-dokumen mereka. Selain itu dalam hal komunikasi, dimana mereka tidak dapat menghubungi siapapun karena komunikasi yang hanya dapat dilakukan melalui alat komunikasi yang ada di ruangan nahkoda kapal, dan hal tersebut dilarang. Hal-hal tersebut berdampak pada meninggalnya empat orang ABK WNI, dan dilarung ke laut (burial at sea) dalam periode Desember 2019 hingga April 2020. Setelah semua perlakuan tersebut selesai dan ABK WNI dapat pulang ke tanah air, mereka tidak menerima gaji yang dijanjikan atas apa yang telah dikerjakannya itu.

Human trafficking dalam Pasal 3 United Nation Protocol to Prevent, Suppress and Punish Trafficking in Persons 2000, adalah perekrutan, pengiriman, pemindahan, penampungan, atau penerimaan seseorang, dengan ancaman atau penggunaan kekerasan, atau bentuk-bentuk pemaksaan lain, penculikan, penipuan, kecurangan, penyalahgunaan kekuasaan atau posisi rentan, atau memberi atau menerima bayaran atau menfaatkan atau memperoleh ijin dari orang yang mempunyai wewenang atas orang lain untuk tujuan eksploitasi. Sedangkan force labour dalam Pasal 2 ayat 1 ILO Forced Labour Convention 1930 (No. 29) adalah semua pekerjaan atau jasa yang dituntut dari setiap orang di bawah ancaman hukuman apapun dan untuk itu orang tersebut tidak menawarkan dirinya secara sukarela.

Kedua kejahatan tersebut termasuk kepada istilah perbudakan modern (modern slavery) yang mengacu kepada suatu perekrutan, pemindahan, penyembunyian atau penerimaan anakanak, perempuan atau laki-laki melalui penggunaan kekerasan, pemaksaan, penyalahgunaan kerentanan, penipuan atau cara lain untuk tujuan eksploitasi, ataupun dapat diartikan sebagai "an exploit of others for personal or commercial gain". Dalam hal ini Indonesia haruslah menjalankan yurisdiksi-nya sebagai suatu negara yang berdaulat, untuk melindungi warga negaranya dan menindak tegas para pelaku kejahatan ini sebagaimana disebutkan tegas dalam Pasal 1 ayat (3) UUD 1945 yang menyatakan: "Negara Indonesia adalah Negara Hukum".

Berdasarkan latar belakang yang telah diuraikan, maka perumusan masalah dalam penelitian ini sebagai berikut: "Bagaimana ketentuan-ketentuan hukum internasional terkait human trafficking dan eksploitasi pekerja?" dan "Bagaimana Yurisdiksi Indonesia di Laut Lepas 
terhadap pelaku kejahatan terhadap anak buah kapal di kapal Long Xing 629 berdasarkan Hukum Internasional?" Selanjutnya, tujuan dalam penelitian ini diuraikan dalam pokok-pokok sebagai berikut:

1. Untuk mengetahui bagaimanakah ketentuan-ketentuan hukum internasional terkait human trafficking dan eksploitasi pekerja.

2. Untuk mengetahui bagaimanakah Yurisdiksi Indonesia di Laut Lepas terhadap pelaku kejahatan terhadap anak buah kapal di kapal Long Xing 629 berdasarkan Hukum Internasional.

\section{B. Metodologi Penelitian}

Peneliti menggunakan metode pendekatan yang dilakukan dalam penelitian ini yaitu pendekatan secara yuridis normatif, dengan teknik pengumpulan data secara studi kepustakaan (library research). Penelitian kepustakaan ini dilakukan untuk mengkaji dan menginterventarisikan bahan hukum primer, bahan hukum sekunder, dan bahan hukum tersier.

\section{Hasil Penelitian dan Pembahasan}

Ketentuan-Ketentuan Hukum Internasional Terkait Human Trafficking dan Eksploitasi Pekerja. Ketentuan mengenai larangan adanya praktek human trafficking dan forced labour sudah terdapat pada tahun 1948 melalui Universal Declaration of Human Rights (UHDR) yang mendeklarasikan bahwa terhadap segala bentuk perbudakan atau penghambaan haruslah dilarang sebagai upaya penegakan hak asasi manusia yang merupakan nilai paling mendasar pada manusia. Kemudian pada perkembangannya terdapat The International Covenant on Civil and Political Rights (ICCPR) dan International Covenant on Economic, Social and Cultural Rights (ECOSOC) bahwa terhadap perbudakan dan perdagangan budak dalam apapun bentuknya haruslah dilarang, karena setiap orang pada dasarnya orang memiliki hak untuk menentukan nasib sendiri dan bebas mengejar perkembangan ekonomi, sosial dan budaya, hal tersebut tentunya bertentagan dengan kedua kejahatan tersebut karena membatasi hak-hak mereka sebagai manusia.

Istilah human trafficking terdapat dalam beberapa instrumen hukum internasional, pada awalnya terdapat dalam ILO Convention No. 182, yang secara spesifik melarang praktek ini terhadap anak usia di bawah usia 18 tahun dan terhadap konvensi ini berlaku hanya kepada negara yang melakukan ratifikasi saja. Selanjutnya dalam Convention on the Elimination of All Forms of Discrimination against Women (CEDAW) yang melarang adanya diskriminasi terhadap perempuan, dalam hal ini negara-negara yang meratifikasi konvensi ini haruslah melarang dan menekan semua bentuk perdagangan perempuan dan eksploitasi pelacuran perempuan, melalui hukum nasional.

Kemudian terdapat United Nations Protocol to Suppress, Prevent and Punish Trafficking in Persons Especially Women and Children supplementing the Convention against Transnational Organized Crime (Protokol Palermo), yang menjelaskan definisi human traffikcing adalah proses perekrutan, pengangkutan, pemindahan, penyembunyian atau penerimaan orang, dengan ancaman atau penggunaan kekerasan atau bentuk-bentuk pemaksaan lainnya, penculikan, penipuan, penipuan, penyalahgunaan kekuasaan atau posisi rentan atau pemberian atau penerimaan pembayaran atau manfaat untuk memperoleh persetujuan dari orang yang memiliki kendali atas orang lain, untuk tujuan eksploitasi.

Dalam protokol ini terdapat dua unsur dalam konvensi sebelumnya dimana dalam konvensi ini istilah trafficking tidak hanya ditujukan kepada subjek tertentu saja melainkan kepada seluruh manusia itu sendiri sehingga terhadap protokol berlaku sebagai instrumen universal (law making treaty) atau dengan kata lain berlaku bagi semua negara, dan semua negara wajib untuk melakukan tindakan yang mencegah dan memerangi perdagangan orang, terutama perempuan dan anak-anak, serta untuk menghukum para pedagang dan untuk melindungi korban dari perdagangan orang, termasuk tindakan legislasi untuk menetapkan human trafficking sebagai tindak pidana. Maka jika di tarik garis lurus, Protokol Palermo inilah yang dijadikan sebagai dasar dalam tindak kejahatan human trafficking dalam hukum internasional saat ini. Terhadap Protokol Palermo sendiri, Indonesia telah meratifikasinya 
melalui Undang-Undang No.14 Tahun 2009 tentang Pengesahan Protocol to Suppress, Prevent and Punish Trafficking in Persons especially Women and Children supplementing the Convention against Transnational Organized Crime, yang berarti Indonesia telah terikat dengan kewajiban dari protokol ini.

Sementara itu mengenai eksplotasi pekerja (forced labour) terdapat dalam ILO Forced Labour Convention 1930 (No. 29) yang pada dasarnya merupakan dasar hukum internasional pertama mengenai adanya force labour, yang memberikan definisi forced labour mengacu kepada pekerjaan yang dilakukan seseorang dengan kondisi berada di bawah ancaman hukuman pihak lain dan orang tersebut tidak menawarkan dirinya secara sukarela, tehadap konvensi ini dapat berlaku secara terbatas karena disebutkan bahwa konvensi ini berlaku bagi negara yang me-ratifikasi saja, dan terhadap negara yang tergabung dengan ILO. Saat itu Hindia Belanda (Indonesia) meratifikasinya melalui Nederland Staatsblad 1933 No. 26 jo 1933 (No. 236) dan dinyatakan berlaku bagi Indonesia dengan Indonesia Staatsblad 1933 No. 261.

Kemudian dalam ILO Abolition of Forced Labour Convention 1957 (No. 105) merupakan kewajiban terhadap negara anggota ILO untuk menekan dan tidak menggunakan segala bentuk forced labour, yang digunakan dalam praktek sebagai hukuman kepada seseorang, metode pembagunan ekonomi, disiplin kerja; hingga sebagai sarana diskriminasi rasial, sosial, kebangsaan atau agama, dan terhadap konvensi ini Indonesia sebagai negara anggota ILO telah meratifikasinya dalam Undang-Undang No.19 Tahun 1999 tentang Pengesahan ILO Convention No.105 Concerning The Abolition of Forced Labour.

Instrumen-instrumen hukum internasional yang dikeluarkan itu merupakan gambaran betapa seriusnya kedua kejahatan tersebut harus diatasi. Instrumen internasional yang terus bertambah sebagai kedua kejahatan tersebut memiliki model dan bentuk yang semakin kompleks dari masa ke masa, di abad ke-20 human trafficking dan force labour termasuk kepada bentuk dari modern slavery. Bentuk-bentuk yang kompleks dari human trafficking dan forced labour, juga menjadi suatu masalah yang serius bagi masyarakat internasional (an serious problem of human mankind), dalam hal ini berperan sebagai negara pengharapan pertama untuk menjadi penjamin penghormatan terhadap hak-hak asasi manusia itu sendiri, baik untuk melegislasi untuk menetapkan human trafficking dan forced labour sebagai tindak pidana, serta menghukum para pelaku dan untuk melindungi korban itu sendiri, yang mana dalam prakteknya tercerminkan dalam Undang-Undang No. 21 Tahun 2007 tentang Pemberantasan Tindak Pidana Perdangan Orang, Undang-Undang No.34 Tahun 2014 tentang Perlindungan Anak, dan Undang-Undang No.13 Tahun 2003 tentang Ketenagakerjaan.

Yurisdiksi Indonesia di Laut Lepas Terhadap Pelaku Kejahatan Kepada Anak Buah Kapal di Kapal Long Xing 629 Berdasarkan Hukum Internasional

Yurisdiksi adalah one of the most obvious form of exercise of sovereign power, dengan adanya yurisdiksi suatu negara dapat melaksanakan tindakan hukum terhadap orang ataupun benda, baik itu mengatur, melaksanakan, dan memaksakan berlaku aturan-aturan hukum yang tidak hanya terbatas terhadap permasahan yang terjadi dalam negeri, namun juga terkait permaslahan yang terjadi diluar batas wilayah negaranya. Kejahatan yang terjadi kepada ABK WNI di kapal Long Xing 629 yang terjadi di laut lepas tersebut maka berlaku teori pulau terapung (floating island theory) yang menyatakan bahwa kapal umum dalam hal ini fishing vessel dipandang sebagai bagian wilayah dimana kapal itu didaftarkan maka yurisdiksi pengadilan atas kejadian-kejadian diatas kapal itu dalam kasus ini adalah negara China.

Terhadap apa yang terjadi kepada ABK WNI di kapal Long Xing 629 itu termasuk kepada bentuk dari kejahatan human trafficking sebagaimana tercantum dalam Pasal 3 huruf (a) Protocol Palermo yakni perekrutan, pengangkutan, pemindahan, penyembunyian atau penerimaan orang, melalui perlakuan atau penggunaan kekerasan atau bentuk-bentuk pemaksaan lainnya, penculikan, penipuan, penyalahgunaan kekuasaan atau penetapan kerentanan memberi atau menerima pembayaran atau manfaat untuk mendapatkan persetujuan dari orang yang memiliki kendali atas orang lain, untuk tujuan eksploitasi. Dari pasal tersebut juga dapat diketahui bahwa human trafficking diidentifikasikan melalui kegiatan, cara, dan tujuan akhirnya, sebagai berikut:

1. Pertama, kegiatannya meliputi perekrutan, pengangkutan, pemindahan, penyembunyian, 
atau penerimaan orang. Dalam kasus ABK WNI di Long Xing 629 ini dilakukan dengan cara perekrutan melaui sponsor yang selanjutnya dihubungkan dengan maining agency;

2. Kedua, cara dilakukannya menggunakan penipuan sebagaimana dijelaskan oleh korban bahwa mereka dijanjikan diberangkatkan ke luar negeri di kapal berbendera Korea Selatan secara legal serta menempatkan ABK sesuai perjanjian, dengan gaji sebesar 4.200 U.S Dollar untuk 14 bulan waktu kerja, namun kenyataannya tidak demikian;

3. Ketiga, tujuan mereka direkrut adalah untuk dijadikan ABK di kapal penangkap ikan, namun dalam prakteknya mereka dipaksa berkeja 15 jam/hari bahkan bisa lebih dari itu dalam kondisi tertentu, dimana dalam kondisi ini mengarah kepada pengertian eksploitasi perkerja (forced labour).

Selain itu terhadap perbuatan yang terjadi kepada ABK WNI di kapal Long Xing 629 juga memenuhi unsur-unsur eksploitasi pekerja (forced labour) yang didasarkan pada Pasal 2 ayat 1 ILO Forced Labour Convention 1930 (No. 29) yang menyebutkan bahwa: "forced or compulsory labour shall mean all work or service which is exacted from any person under the menace of any penalty and for which the said person has not offered himself voluntarily". Adapun unsur-unsur yang dimaksud adalah sebagai berikut:

1. "All work or service", mengacu kepada pekerjaan para WNI yakni menjadi seorang $\mathrm{ABK}$.

2. "Any person", mengacu kepada ABK WNI tersebut;

3. "Menace of any penalty", mengacu kepada ancaman denda yang menjadi senjata utama para pelaku dimana apabila para ABK WNI tidak mengikuti perintah yang telah diperintahkannya, mereka akan dikenakan sanksi berupa potongan gaji hingga broken contract; dan

4. "Not offered himself voluntarily", mengacu kepada jam kerja yang melebihi dari batas jam kerja pada umumnya tanpa ada persetujuan dari dirinya itu sendiri atau secara sukarela dari pekerja.

Terhadap kejahatan human trafficking dan forced labour yang terjadi kepada ABK WNI kapal Long Xing 629, juga termasuk kepada istilah modern slavery yang mana menunjuk kepada "the recruitment, movement, harbouring or receiving of children, women or men through the use of force, coercion, abuse of vulnerability, deception or other means for the purpose of exploitation". Dalam hal ini terhadap kasau ini telah memenhi karakteristik modern slavery sebagai berikut:

1. Pertama, kegiatannya berupa perekrutan (penerimaan orang), dimana para calon $A B K$ WNI direkrut oleh sponsor untuk selanjutnya dihubungkan dengan maining agency;

2. Kedua, terkait cara yang dilakukannya menggunakan penipuan (deception) dimana korban bahwa mereka dijanjikan diberangkatkan ke luar negeri di kapal berbendera Korea Selatan secara legal serta menempatkan ABK sesuai perjanjian, dengan gaji sebesar 4.200 U.S Dollar untuk 14 bulan waktu kerja, namun kenyataannya tidak demikian, karena dalam pelaksanaan kerjanya mereka diancam dengan kekerasan fisik (threat or use of force) yang membuat para ABK WNI tidak berani melawan ketika mereka diperlakukan tidak baik, dan adapula penahanan dokumen (withholding documents).

3. Ketiga, dilihat dari tindakan yang dilakukan terhadap ABK WNI di kapal Long Xing 629 tersebut mereka dipaksa berkeja 15 jam/hari bahkan bisa lebih dari itu dalam kondisi tertentu, dimana dalam kondisi ini mengarah kepada istilah forced labour.

Terhadap hal ini Indonesia memiliki kewenagan yurisdiksi personal pasif, hal ini berkaitan dengan adanya kerugian baik materil ataupun non materil (human trafficking atau forced labour) yang dialami oleh ABK WNI di kapal Long Xing 629 tersebut, dengan dasar bahwa setiap negara berhak melindungi warga negaranya di luar negeri, mengingat tidak ada usaha yang dilakukan oleh pemerintahan China untuk menghukum perusahaan perikanan tersebut, maka sesuai dengan yurisdiksi personal pasif, apabila negara teritorial di mana tindak pidana itu terjadi tidak menghukum orang yang menyebabkan kerugian tersebut, maka negara asal korban berwenang menghukum tindak pidana itu, dalam kasus ini pemerintah Indonesia dapat melayangkan gugatan terhadap perusahaan penangkap ikan Dalian Ocean Fishing Co., 
Ltd.

Hal tersebut juga sesuai dengan Pasal 4 KUHP yang menyebutkan bahwa ketentuan pidana dalam perundang-undangan Indonesia diterapkan bagi setiap orang yang melakukan diluar Indonesia, dalam hal pelaksanaannya didasarkan dengan pemikiran bahwa setiap Negara yang berdaulat berhak melindungi kepentingan hukumnya untuk menangani kejahatan human trafficking serta forced labour yang merugikan warganegaranya yakni ABK WNI di kapal Long Xing 629. Sebagai contoh kasus Sorihin dan Abdul Fatah di kapal Sea Queen II di Samudera Pasifik, yang menggugat pemilik dan operator kapal penangkap ikan komersial (commercial fishing vessel) berbendera Amerika Serikat, dimana dimungkinkan setiap negara menuntut kejahatan terhadap warga negaranya di luar negeri dalam rangka untuk melindungi warganegaranya.

Kemudian selain dapat berlaku yurisdiksi personal aktif, dapat berlaku juga yurisdiksi universal (universal jurisdiction). Hal itu didasarkan kerena kedua kejahatan itu termasuk kepada jenis kejahatan perbudakan modern (modern slavery), modern slavery sendiri merupakan perkembangan dari istilah slavery, slavery sendiri merupakan salah satu bentuk kejahatan internasional (international crimes) yang disebutkan dalam Draft Code of Crimes Against the Peace and Security of Mankind 1954, ataupun dalam Pasal 7 ayat (1) huruf c The Rome Statute of the International Criminal Court (Statuta Roma) 1998 mengenai kualifikasi kejahatan Crimes Against Humanity (CAH) yang termasuk kepada core crimes yang merupakan pelanggaran terhadap jus gentium (delicto jus gentium).

Selain itu karena terhadap apa yang terjadi kepada ABK WNI di kapal Long Xing 629 itu dapat disebut sebagai modern slavery. Itilah slavery sendiri diatur dalam Pasal 99 United Nations Convention on the Law of the Sea 1982 (UNCLOS 1982) disebutkan bahwa:

"Every State shall take effective measures to prevent and punish the transport of slaves in ships authorized to fly its flag and to prevent the unlawful use of its flag for that purpose. Any slave taking refuge on board any ship, whatever its flag, shall ipso facto be free" (Setiap Negara harus mengambil langkah-langkah efektif untuk mencegah dan menghukum pengangkutan budak di kapal yang diberi wewenang untuk mengibarkan benderanya dan untuk mencegah penggunaan yang tidak sah dari benderanya untuk tujuan itu. Setiap budak yang berlindung di atas kapal apa pun, apa pun benderanya, haruslah bebas).

Para ahli menyatakan terhadap ketentuan tersebut berlaku pemberanan universal karena slavery sendiri merupakan kejahatan terhadap kebebasan seseorang (the gravity of the crime against a person's liberty). Kemudian berdasarkan Declaration of the Congress of Vienna 1815 memutuskan bahwa perdagangan budak (transport of slaves) memiliki tingkat kejahatan yang setara layaknya pembajakan (piracy), hal itu syaratkan bahwa perbudakan (atau setidaknya untuk aspek perdagangan budak) terjadi setelah di laut lepas, dalam hal ini yurisdiksi universal diberikan dengan tujuan untuk menghentikan praktek perbudakan yang terjadi disana, yang didasarkan pada tujuan kemanfaatan bukan kepada sifat kejahatannya itu sendiri (inherent nature).

Selain itu terhadap adanya praktek kejahatan tersebut jelas melanggar hukum kebiasaan internasional, dan kepada kejahatan internasional tersebut secara universal dikutuk (universally condemned), sehingga semua negara tanpa terkecuali wajib untuk mengadili pelakunya mengingat kejahatan slavery dipandang sebagai a problem of serius corcern to all nations. Kemudian slavery sendiri termasuk kepada kejahatan internasional (international crimes) sebagaimana disebutkan oleh sebagian ahli/praktisi kejahatan internasional yang juga memperluas penerapan yurisdiksi universal untuk meningkatkan upaya penegakan hukum (law enforcement). Hal tersebut dimaksudkan untuk memungkinkan negara melakkan penuntutan terhadap kejahatan-kejahatan tersebut, dalam hal ini bahkan ketika beberapa negara gagal melakukan upaya serius untuk mengkriminalisasi perilaku tersebut.

Selain itu slavery/modern slavery sendiri merupakan salah satu jenis kejahatan kemanusiaan (crimes against humanity) karena dinilai dapat membahayakan nilai-nilai kemanusiaan dan keadilan, dan terhadap kejahatan terhadap kemanusiaan merupakan musuh seluruh umat manusia (hostis humanis generis) yang mana penuntutan terhadap pelakunya merupakan kewajiban seluruh umat manusia (obligatio erga omnes). Selain itu kejahatan 
tersebut juga telah memenuhi karakteristik yurisdiksi universal sebagaimana disebutkan oleh Ilias Bantekas dan Susan Nash dalam bukunya "International Criminal Law". Jadi dapat simpulkan bahwa kejahatan yang terjadi kepada ABK WNI di kapal Long Xing 629 tersebut termasuk kepada jenis kejahatan terhadap kemanusiaan (based on crimes against humanity), diperkuat dengan dasar bahwa kejahatan tersebut dilakukan di lokasi yang tidak tunduk pada otoritas negara manapun (locations not subject to the authority of any State) dalam hal ini laut lepas, maka berlaku yurisdiksi universal.

\section{Kesimpulan}

Berdasarkan pembahasan dalam penelitian ini, peneliti menyimpulkan beberapa hasil penelitian sebagai berikut:

1. Praktek human trafficking dan forced labour sendiri merupakan kejahatan terhadap kebebasan seseorang (the gravity of the crime against a person's liberty) sebagaimana selanjutnya dicantumkan dalam Universal Declaration of Human Rights (UHDR) The International Covenant on Civil and Political Rights (ICCPR), dan International Covenant on Economic, Social and Cultural Rights (ECOSOC). Dalam perkembagannya, terdapat beberapa instrumen Internasional yang mengatur mengenai human trafficking seperti: ILO Convention Concerning the Prohibition and Immediate Action for the Elimination of the Worst Forums of Child Labor (ILO No. 182); Convention on the Elimination of All Forms of Discrimination against Women (CEDAW); United Nations Protocol to Suppress, Prevent and Punish Trafficking in Persons especially Women and Children supplementing the Convention against Transnational Organized Crime (Protokol Palermo); dan South Asian Association for Regional Cooperation Convention on Combating Trafficking in Women and Children for Prostitution. Sedangkan forced labour tercantum dalam beberapa instrumen Internasional yang lain, seperti: ILO Forced Labour Convention, 1930 (No. 29); ILO Abolition of Forced Labour Convention, 1957 (No. 105); ILO Worst Forms of Child Labour Convention, 1999; dan The Trafficking Victims Protection Act, 2000.

2. Kejahatan yang terjadi terhadap ABK WNI di kapal Long Xing 629 telah menuhi karakteristik human trafficking dalam Protocol to Prevent, Suppress ang Punish Traffikking in Person, Especially Women and Children, Supplement the United Nation Convention Againtst Transnational Organization Crime 2000 dan forced labour dalam ILO Forced Labour Convention 1930 (No. 29). Kedua kejahatan tersebut juga termasuk kepada istilah modern slavery, maka dari itu terdapat dua kewenangan yurisdiksi Indonesia terhadap kejahatan yang terjadi terhadap ABK WNI di kapal Long Xing 629 yakni yurisdiksi personal pasif yang didasarkam pada adanya kerugian baik materil ataupun non materil yang dialami oleh ABK WNI di kapal Long Xing 629, dan yurisdiksi universal (universal jurisdiction) yang didasarkan bahwa kejahatan tersebut merupakan bentuk dari slavery/modern slavery yang merupakan salah satu jenis kejahatan kemanusiaan (crimes against humanity) yang merupakan core crimes, karena karena dinilai dapat membahayakan nilai-nilai kemanusiaan dan keadilan sehingga dipandang sebagai a problem of serius corcern to all nations.

\section{Daftar Pustaka}

[1] Devina Halim. Kronologi Kasus ABK Indonesia di Kapal Long Xing 629 Menurut Polisi. Available from: https://nasional.kompas.com/read/2020/05/21/06420851/begini-kronologikasus-abk-wni-di-kapal-long-xing-629-menurut-polisi?.

https://opac.perpusnas.go.id/DetailOpac.aspx?id=618936

[2] Elizabeth Such, dkk, Research and Analysis: Modern Slavery and Public Health. Public Health England: United Kingdom. 2017

[3] Food and Agriculture Organization (FAO) Departement. The state of world Fisheries and Aquacullture. FAO, 2012.

[4] Ilias Bantekas \& Susan Nash. International Criminal Law. Routledge-Cavendish: New York. 2007 
[5] International Labour Organization. Report III (1B): Giving globalization a human face (General Survey on the fundamental Conventions). Available from: https://www.ilo.org/ilc/ILCSessions/previous- sessions/101stSession/reports/reportssubmitted/WCMS_174846/lang--en/index.htm

[6] Marcia Audita, dkk (ed), Pengakuan Lengkap ABK WNI Korban Perbudakan Kapal China Long Xing 629. Available from:. https://kumparan.com/kumparannews/pengakuan-lengkapabk-wni-korban-perbudakan-kapal-china-long-xing-629-1ttWhDZgznR/full

[7] M. Cherif Bassiouni. International Criminal Law. Transnational Publishers: New York, 1986

[8] M. Cherif Bassiouni. Universal Jurisdiction for International Cnmes: Historical Perspectives and Contemporary Practice. Virginia Journal of International Law. 2001

[9] Oxford City Council. Modern Slavery and Exploitation. Diakses pada tanggal 12 Januari 2022.

Avaliable

from: https://www.oxford.gov.uk/info/20101/community_safety/1328/modern_slavery_and_expl oitation

[10] Reynolds, John. Universal Jurisdiction to Prosecute Human Trafficking: Analyzing the Practical Impact of a Jurisdictional Change in Federal Law. Hastings International and Comparative Law Review. Vol. 34. No. 2. 2011

[11] Riza Amalia (dkk.). Perlindungan Hak Anak Buah Kapal Dalam Kerangka Hukum Nasional Dan Internasional. Universitas Lampung: Lampung. 2018. 